\title{
Iron Deficiency Anemia in Inflammatory Bowel Disease: What Do We Know?
}

\author{
Tamás Resál, Klaudia Farkas and Tamás Molnár* \\ Gastroenterology Unit, Department of Medicine, University of Szeged, Szeged, Hungary
}

One of the most common extraintestinal manifestations of inflammatory bowel disease is iron deficiency anemia. It is often an untreated condition that significantly impairs patients' quality of life and elevates mortality and morbidity. Although it is often accompanied by mild symptoms (e.g., fatigue, lethargy), it can provoke severe health conditions, such as dyspnea, palpitation, angina, and mental disorders, and increases hospitalization and mortality rate as well. As anemia develops through several pathomechanisms, such as occult bleeding, chronic inflammation, and medicines (e.g., methotrexate), treating anemia effectively requires to manage the underlying pathological changes as well. Based on international publications and data, it is a frequent condition and more frequent in pediatrics. According to Goodhand et al., iron deficiency is present in more than $60 \%$ of children, whereas only $14 \%$ of them received oral iron therapy.

OPEN ACCESS

Edited by:

Uri Kopylov,

Sheba Medical Center, Israel

Reviewed by:

Hakan Akin,

Marmara University, Turkey

Ali Alali,

Mubarak Al Kabeer Hospital, Kuwait

*Correspondence:

Tamás Molnár molnaribd@hotmail.com

Specialty section:

This article was submitted to

Gastroenterology,

a section of the journal

Frontiers in Medicine

Received: 27 March 2021

Accepted: 17 May 2021

Published: 01 July 2021

Citation:

Resál T, Farkas K and Molnár T (2021)

Iron Deficiency Anemia in

Inflammatory Bowel Disease: What Do

We Know? Front. Med. 8:686778.

doi: 10.3389/fmed.2021.686778 Compared to adult patients, $22 \%$ have iron deficiency, and $48 \%$ of them received oral and $41 \%$ intravenous iron therapy. Miller et al. also highlighted that among young patients iron deficiency anemia is a frequent condition, as almost $50 \%$ of the patients were anemic in their cohort. European Crohn's and Colitis Organisation's statements are clear regarding the diagnosis of iron deficiency anemia, and the iron supplementation as well. Third-generation parenteral iron supplementations seem to be safer and more effective than oral iron pills. Oral iron in many cases cannot replace the iron homeostasis as well; furthermore, it can provoke dysbiosis, which can potentially lead to relapse. As a result, we claim that both oral and parenteral should be used more frequently; furthermore, intravenous iron could replace oral medicines as well in certain cases. Despite the fact that iron deficiency anemia is examined by many aspects, further questions can be raised. Can it imply underlying pathological lesions? Are both oral and intravenous iron therapy safe and effective? When and how are they used? We demand that more studies should be conducted regarding these issues.

Keywords: inflammatory bowel disease, iron deficiency anemia, iron supplementation, anemia, parenteral iron supplementation, oral iron supplementation

\section{INTRODUCTION}

Inflammatory bowel disease [IBD: Crohn disease (CD), ulcerative colitis (UC)] is a chronic, immune-mediated disease that impairs patients' quality of life (QoL), and it is associated with many comorbidities. One of the most common concomitant diseases is iron deficiency anemia (IDA), which also worsens the condition of patients and mostly remains untreated (1). It can occur at any 
stage of IBD and can be the first symptom of the disease as well. It is often associated with frequent chronic activity, but can also be encountered without clinical signs of activity. In such cases, the IDA diagnosis raises the possibility of asymptomatic, subclinically occurring inflammation and mucosal damage in the presence of long-term chronic activity that damages the condition and function of the intestine (1).

\section{Frequency of IDA}

At the time of the diagnosis, the prevalence of IDA in patients younger than 18 years is approximately $41-75 \%$ (2), whereas in adult patients it is also high; however, it varies with wide ranges, from 6 to $74 \%$ (3). According to a Swedish study, conducted by Sjöberg et al., the prevalence of IDA is almost twice as high in children (55\%) as in adult patients $(27 \%)$ at the time of the diagnosis. Furthermore, they found significant difference as well in the prevalence of IDA among patients with $\mathrm{CD}$, compared to UC, following the first year after the diagnosis. They also found that anemia in $\mathrm{CD}$ was more common in colonic engagement, and in UC, extensive inflammation increased the prevalence (4). Eriksson et al. conducted a study to assess the incidence, prevalence, and clinical outcome of anemia in IBD, comparing $\mathrm{CD}$ and $\mathrm{UC}$, and they found as well that CD is associated with higher prevalence and a worse outcome regarding the resolution of anemia (5).

\section{Symptoms and Clinical Role}

Generally speaking, it should be highlighted that patients with IDA claim to have decreased QoL. In a Spanish study, conducted by García-López et al., it was found that treating IDA improves the QoL, regardless of the symptoms of IBD (6).

As iron plays key role in the function of many cells (e.g., erythrocyte, macrophage), cellular proteins, and enzymes (e.g., cytochromes, myoglobin), the symptoms of IDA vary over a wide range $(7,8)$. Key symptoms, such as shortness of breath, palpitation, tachycardia, and even angina, occur because of the hypoxemia. As a result of the decreased blood oxygen level, there is a compensatory decrease in intestinal blood flow, which may cause motility disorder, malabsorption, nausea, weight loss, and abdominal pain. Central hypoxia may lead to headache, vertigo, and lethargy, as well as cognitive impairment, and several studies proved that normalizing anemia improves cognitive functions (9-12) (Table 1).

Michailidou et al. compared the risk of postoperative complications between anemic and nonanemic patients. In their study consisting of more than 15,000 people, it was found that patients with anemia were more likely to have postoperative complications (e.g., morbidity and mortality rate; undesirable cardiovascular, renal, pulmonary, and wound healing complications; postoperative sepsis and shock) (13).

\section{Etiology of Anemia in IBD}

The most common causes of anemia in IBD are IDA, chronic inflammation, and anemia of mixed origins, whereas $B_{12}$ deficiency and folic acid deficiency (mostly due to medications) belong to the less common causes. In addition, it may also occur
TABLE 1 | Symptoms of iron deficiency anemia.

\begin{tabular}{|c|c|}
\hline Nervous system & $\begin{array}{l}\text { Headache, lethargy, vertigo, syncope, cognitive } \\
\text { impairment, depression }\end{array}$ \\
\hline Cardiovascular system & $\begin{array}{l}\text { Palpitation, tachycardia, hypotension, angina, ischemic } \\
\text { electrocardiographic signs, cardiac failure }\end{array}$ \\
\hline Respiratory system & Shortness of breath \\
\hline Skin & Paleness, alopecia, cold intolerance \\
\hline $\begin{array}{l}\text { Gastrointestinal } \\
\text { symptoms }\end{array}$ & $\begin{array}{l}\text { Anorexia, nausea, motility disturbances, angular } \\
\text { stomatitis, glossitis (Plummer-Vinson syndrome) }\end{array}$ \\
\hline Immune system & Disorder of the innate and adaptive immune system \\
\hline Urogenital symptoms & Decreased libido, menstrual disorders \\
\hline General symptoms & Decreased quality of life, lower physical activity \\
\hline
\end{tabular}

TABLE 2 | Ethiology of anemia in IBD.

\begin{tabular}{ll}
\hline Most common causea of anemia in IBD & - Iron deficiency anemia \\
& - Anemia of chronic inflammation \\
& - Anemia of mixed origins \\
Less common causes & - Folic acid/B B $_{12}$ deficiency \\
Rare causes & - Hemolysis \\
& - Myelodysplastic syndrome \\
& - Aplasia \\
& - Protein starvation \\
& - Liver disease
\end{tabular}

because of hemolysis, myelodysplastic syndrome/medicationinduced aplasia, protein starvation, and liver disease (e.g., primary sclerosing cholangitis) $(14,15)$ (Table 2$)$.

\section{Pathophysiology of IDA}

In IBD, the IDA can develop through several pathomechanisms (16):

I. Intestinal mucosal damage resulting in occult, chronic blood loss

II. Chronic inflammation

a) Reduced iron-absorbing capacity of enterocytes

b) Iron is trapped in macrophages

c) Inhibition of the erythropoietin and the differentiation/proliferation of the erythroid progenitor cells

Cytokines and acute-phase proteins cause changes in iron homeostasis during inflammation. Hepcidin plays the central role in the regulatory process. It is an antimicrobial protein, produced by the liver in case of iron surplus and in inflammation, triggered by interleukin 6 and lipopolysaccharides. Hepcidin binds to the iron-transporting ferroportin receptor and degrades it, which results in decreased iron transport from the enterocytes to the circulation, and causes retention of the iron in the monocytes/macrophages; these processes are enhanced by antitumor necrosis factor $\alpha$. In addition, hepcidin reduces the absorption of the $\mathrm{Fe}^{2+}$ from the duodenum, through the inhibition of the DMT1 (divalent metal transporter 1) (17).

Transferrin is the main iron carrier protein, and during inflammation, acute-phase proteins (e.g., $\alpha-1$ antitrypsin) bind 
TABLE 3 | Pathomechanisms of different type of anemias in IBD.

\begin{tabular}{|c|c|}
\hline Iron deficiency anemia & $\begin{array}{l}\text { Chronic blood loss } \\
\text { Reduced absorption of } \mathrm{Fe}^{2+} \text { (bowel resection, } \\
\text { inflammation) } \\
\text { Anorexia }\end{array}$ \\
\hline $\begin{array}{l}\text { Anemia of chronic } \\
\text { disease }\end{array}$ & $\begin{array}{l}\text { Iron retention in monocytes/macrophages } \\
\text { Reduced absorption of } \mathrm{Fe}^{2+} \text { (inflammation) } \\
\text { Reduced biological half-life of erythrocytes (e.g., } \\
\text { erythrophagocytosis) } \\
\text { Inhibition of erythropoiesis }\end{array}$ \\
\hline Other origin & $\begin{array}{l}\text { Vitamin deficiency (B12, folic acid) } \\
\text { Drug-induced bone marrow suppression } \\
\text { (methotrexate, azathioprine) }\end{array}$ \\
\hline
\end{tabular}

to transferrin receptors and inhibit the iron uptake in the erythroid progenitors cells, resulting in reduced differentiation and proliferation (18).

\section{Diagnosis/Differential Diagnosis in Anemia}

Anemia and iron homeostasis should be monitored regularly in IBD (depending on activity and the type of the treatment):

- At the time of diagnosis

- During activity-every 3 months

- In remission-every 6 to 12 months

Vitamin $B_{12}$ and folic acid should be monitored every year, in case of presence of risk factors (e.g., resection, pouch, extensive ileal disease) every 3-6 months.

The diagnosis of anemia is assessed by the World Health Organization (WHO) diagnostic criteria, depending on the gender and age of the patients (Table 3 ).

\section{Differential Diagnosis in Anemia}

According to the European Crohn's and Colitis Organization (ECCO) recommendations, the following parameters should be monitored if hemoglobin is below normal (Table 4): erythrocyte count, serum ferritin, C-reactive protein (CRP) concentration, transferrin saturation, reticulocyte count, erythrocyte width distribution, and mean corpuscular volume. Ferritin is an acutephase protein produced by the liver, and it is responsible for binding and storing iron in the liver, spleen, and reticuloendothelial system. It is reduced in case of iron deficiency and elevated in inflammation. Hence, in determining the cause of anemia in IBD, it is important to assess disease activity based on disease scoring systems (Crohn's Disease Activity Index and Mayo score) and serum CRP and fecal calprotectin levels. In case of inflammation, transferrin saturation helps in differential diagnosis. Transferrin saturation (accepted normal range $=$ $20-45 \%)$ is lower in inflammation, liver disease, malignancy, nephrotic syndrome, and anorexia, whereas it is elevated in iron deficiency and pregnancy (19).

IDA (19):

a) Anemia based on WHO criteria (low hemoglobin and hematocrit). Clinically and endoscopically, no inflammation
TABLE 4 | World Health Organization's anemia criteria.

\begin{tabular}{lcc}
\hline & Hemoglobin (g/dL) & Hematocrit(\%) \\
\hline Children between 6 months and 5 years & 11 & 33 \\
Children between 5 and 11 years & 11.5 & 34 \\
Children between 12 and 13 years & 12 & 36 \\
Pregnant women & 11 & 36 \\
Women & 12 & 33 \\
Men & 13 & 39
\end{tabular}

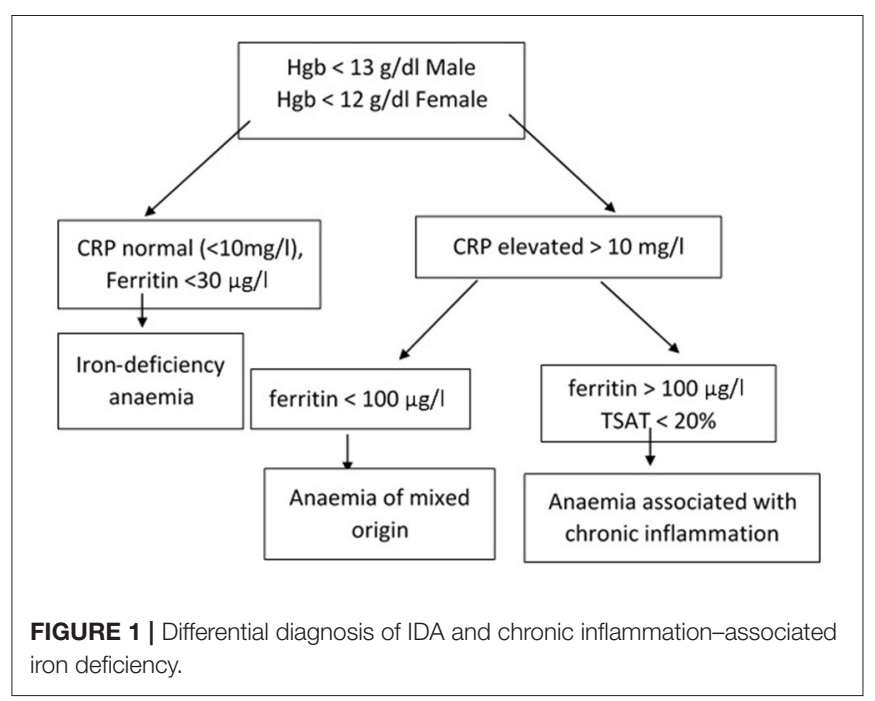

can be found, CRP level is normal, and serum ferritin is $<30 \mu \mathrm{g} / \mathrm{L}$.

b) Anemia based on WHO criteria. Clinically and/or endoscopically, inflammation can be found, CRP is elevated, and ferritin is $<100 \mu \mathrm{g} / \mathrm{L}$.

Anemia associated with chronic inflammation:

- Anemia based on WHO criteria. Clinically and/or endoscopically, inflammation can be found, CRP is elevated, ferritin is $>100 \mu \mathrm{g} / \mathrm{L}$, and transferrin saturation is $<20 \%$.

Anemia of mixed origin:

- Anemia based on WHO criteria. Clinically and/or endoscopically, inflammation can be found, CRP is elevated, and ferritin is between 30 and $100 \mu \mathrm{g} / \mathrm{L}$ (Figure 1).

\section{Iron Supplementation}

Goodhand et al. pointed out how undertreated the IDA is in IBD. In children (88\%) and adolescents (83\%), the incidence of IDA is much higher compared to that in adults (55\%), and only a small proportion of patients received oral (children 13\%, adolescents $30 \%$, adults $48 \%$ ) or parenteral iron supplementation (children $0 \%$, adolescents $30 \%$, adults $41 \%$ ) (20).

In addition to improving the QoL, the goal of iron supplementation is to normalize hemoglobin, serum ferritin, and transferrin saturation and to refill iron stores (ferritin $>100 \mathrm{~g} / \mathrm{L}$ ). 
TABLE 5 | Administration of parenteral iron replacement.

\begin{tabular}{lcc}
\hline Hemoglobin $(\mathbf{g} / \mathbf{d L})$ & Body weight $<\mathbf{7 0 ~ k g}$ & Body weight $\geq \mathbf{7 0 ~} \mathbf{~ g g}$ \\
\hline $10-12$ (Female) & $1,000 \mathrm{mg}$ & $1,500 \mathrm{mg}$ \\
$10-13$ (Male) & & \\
$7-10$ & $1,500 \mathrm{mg}$ & $2,000 \mathrm{mg}$
\end{tabular}

Based on the recommendation of the ECCO (19):

Iron supplementation is recommended to all patients with anemia associated with iron disorder. If iron deficiency exists without anemia, iron supplementation requires consideration of the patient's individual clinical status, as there is no evidence in IBD regarding the efficacy of the treatment (19).

Oral iron supplementation is recommended to every patient with IDA with hemoglobin $>10 \mathrm{~g} / \mathrm{dL}$ in case of remission (no clinical/endoscopic activity, normal CRP level). The recommended oral iron intake is $100 \mathrm{mg}$ /day for adults (higher doses are not recommended), and $2-3 \mathrm{mg} / \mathrm{kg}$ body weight per day in children. An acceptable therapeutic response is an increase of $2 \mathrm{~g} / \mathrm{dL}$ in hemoglobin over 4 weeks. If there is intolerance, adverse effects or unsatisfactory therapeutic response is present, intravenous iron therapy is recommended (19).

Parenteral iron supplementation is recommended as a first choice in IDA in case of active IBD (elevated CRP levels and/or clinically active IBD), or hemoglobin level $<10 \mathrm{~g} / \mathrm{dL}$, or previous intolerance to iron supplementation is present. If the elevation is $<2 \mathrm{~g} / \mathrm{dL}$ in hemoglobin level after 4 weeks' therapy, it is recommended to complete the treatment with Erythropoietin (EPO) stimulant. The required iron intake is estimated based on the body weight and the hemoglobin, as it is more effective in patients with IBD suffering from iron deficiency than the traditional Ganzoni formula (19) (Table 5).

Following the resolution of IDA with parenteral iron supplementation, ferritin level is recommended to be maintained above $400 \mu \mathrm{g} / \mathrm{L}$ to prevent short-term recurrence. After successful iron supplementation, patients should be monitored every 3 months in the first year following the correction and every 6-12 months thereafter (including hemoglobin, ferritin, transferrin saturation, CRP). Recurrent anemia may indicate underlying inflammation despite clinical and biochemical remission. The goal of preventive treatment is to keep ferritin and hemoglobin at normal levels. Reinitiation of intravenous iron supplementation is recommended in cases where the ferritin level falls below $100 \mu \mathrm{g} / \mathrm{L}$ or the hemoglobin level is $<12-13 \mathrm{~g} / \mathrm{dL}$ (female/male) (19).

When considering between oral and intravenous iron therapy, the advantages and disadvantages of the therapeutic approaches should be considered as well (21-23).

\section{Oral Iron Supplementation}
a. $\frac{\text { Advantages }}{\text { Low cost }}$
Easier to implement in daily practice
More accessible
Effective in good intestinal absorption

b. Disadvantages

\section{Compliance issues}

Certain foods reduce iron absorption (e.g., tea, coffee, dairy products, fiber)

Certain medications reduce iron absorption

i. Multivitamin/dietary supplements $\left(\mathrm{Ca}^{2+}, \mathrm{Zn}^{2+}, \mathrm{Cu}^{2+}\right)$

ii. Antacids, $\mathrm{H}_{2}$ blockers, PPI

iii. Quinolones, tetracyclines

Dysbiosis

Dysbiosis induced relapse

Side effects are more common compared to parenteral iron suppl.
i. Nausea
ii. Abdominal pain
iii. Diarrhea
iv. Constipation

\section{Parenteral Iron Supplementation}

a. Advantages

More effective

Fast correction of iron homeostasis

Safe and well tolerated

Fewer side effects

Effective in inflammation

The condition of the mucosa does not influence the efficacy

b. Disadvantages
Higher cost
Harder to implement in daily practice
Potential risk of iron overload
Potential risk of anaphylaxis
Possibility of hypophosphatemia

\section{Parenteral Iron Supplementation}

Intravenous iron supplementations consist of an $\mathrm{Fe}^{3+}$ core and a carbohydrate layer. The side effect profile, clearance, tolerable dose, and duration of the infusion are dependent on the magnitude of the core and quality of the carbohydrate layer. The different generations of intravenous iron supplementation comprised different carbohydrate layers (24).

- First generation-high-molecular-weight iron dextran

- Second generation-low-molecular-weight iron dextran
a. Ferrous gluconate
b. Iron sucrose

- Third generation
a. Ferumoxytol
b. Iron carboxymaltose
c. Iron isomaltoside

The disadvantage of the HMWID is the higher probability of anaphylactic reaction/side effects; because of that, it is advised to use higher-generation products. The representatives of the second generation are more efficient with fewer side effects; however, they are not as stable complexes as the representatives of the third-generation preparations; consequently, they can only 
be administered in low doses, and so they require frequents visits. Third-generation preparations are much more efficient, with minimal side effect profile; furthermore, they can be implemented easier in the daily practice. These formulations are more stable, so they can be administered in higher doses, resulting in faster correction of the iron homeostasis, and the duration of the infusion is lesser $(23,25)$.

\section{DISCUSSION}

Anemia and IDA are common consequences of IBD in the developed world. Despite that we know how frequent it is, physicians tend to pay less attention to treat it, even though it affects the course of the disease and heavily reduces the patients' QoL. Although modern medicine knows many facts about the pathophysiology of anemia and IDA, and there are many efficient agents in the therapeutic arsenal, it still raises relevant questions. However, the ECCO's recommendations are clear; we would like to highlight that it should be still a matter of individual judgment, and in certain cases, parenteral iron supplementation should be the choice, instead of oral, because of the side effects. Based on international publications and data, as intravenous iron supplementation tends to be more efficient and safe in IBD, we claim that more studies should be conducted regarding third-generation agents and clarify the boundary line in the recommendations. However, to sum up, we

\section{REFERENCES}

1. Jimenez KM, Gasche C. Management of Iron Deficiency Anaemia in Inflammatory Bowel Disease. Acta Haematol. (2019) 142:30-6. doi: 10.1159/000496728

2. Wiskin AE, Fleming BJ, Wootton SA, Beattie RM. Anaemia and iron deficiency in children with inflammatory bowel disease. J Crohns Colitis. (2012) 6:687-91. doi: 10.1016/j.crohns.2011.12.001

3. Bergamaschi G, Di Sabatino A, Albertini R, Ardizzone S, Biancheri P, Bonetti E, et al. Prevalence and pathogenesis of anemia in inflammatory bowel disease. Influence of anti-tumor necrosis factor-alpha treatment. Haematologica. (2010). 95:199-205. doi: 10.3324/haematol.2009.009985

4. Sjöberg D, Holmström T, Larsson M, Nielsen AL, Holmquist L, Rönnblom A. Anemia in a population-based IBD cohort (ICURE): still high prevalence after 1 year, especially among pediatric patients. Inflamm Bowel Dis. (2014) 20:2266-70. doi: 10.1097/MIB.0000000000000191

5. Eriksson C, Henriksson I, Brus O, Zhulina Y, Nyhlin N, Tysk C et al. Incidence, prevalence and clinical outcome of anaemia in inflammatory bowel disease: a population-based cohort study. Aliment Pharmacol Ther. (2018) 48:638-45. doi: 10.1111/apt.14920

6. García-López S, Bocos JM, Gisbert JP, Bajador E, Chaparro M, Castaño C, et al. High-dose intravenous treatment in iron deficiency anaemia in inflammatory bowel disease: early efficacy and impact on quality of life. Blood Transfus. (2016) 14:199-205. doi: 10.2450/2016.0246-15

7. Kaitha S, Bashir M, Ali T. Iron deficiency anemia in inflammatory bowel disease. World J Gastrointest Pathophysiol. (2015) 6:62-72. doi: 10.4291/wjgp.v6.i3.62

8. Pickett JL, Theberge DC, Brown WS, Schweitzer SU, Nissenson AR. Normalizing hematocrit in dialysis patients improves brain function. Am J Kidney Dis. (1999) 33:1122-30. doi: 10.1016/S0272-6386(99)70150-2

9. Cappellini MD, Musallam KM, Taher AT. Iron deficiency anaemia revisited. J Intern Med. (2020) 287:153-70. doi: 10.1111/joim.13004

10. DeLoughery TG. Iron deficiency anemia. Med Clin North Am. (2017) 101:319-32. doi: 10.1016/j.mcna.2016.09.004

11. Çekiç C, Ipek S, Aslan F, Akpinar Z, Arabul M, Topal F, et al. The effect of intravenous iron treatment on quality of life in inflammatory bowel disease demand that both oral and intravenous iron treatments should be more widespread.

\section{AUTHOR CONTRIBUTIONS}

All authors listed have made a substantial, direct and intellectual contribution to the work, and approved it for publication.

\section{FUNDING}

This work was supported by the research grants of the National Research, Development and Innovation Office (Grant ID: 125377, 129266, and 134863), by the National Excellence Programme (20391-3/2018/FEKUSTRAT to KF), by the New National Excellence Program of the Ministry of Human Capacities (UNKP-19-4-SZTE-44, UNKP-20-5-SZTE-161 to KF), Janos Bolyai Research Grant (BO/00598/19/5) and the Géza Hetényi Research Grant (to KF) by the Faculty of Medicine, University of Szeged.

\section{ACKNOWLEDGMENTS}

The authors would like to take this opportunity to thank Mariann Rutka MD. Ph.D. and Anita Bálint MD. Ph.D., for suggesting we publish this article in Frontiers in Medicine.

patients with nonanemic iron deficiency. Gastroenterol Res Pract. (2015) 2015:582163. doi: $10.1155 / 2015 / 582163$

12. Ebner N, Jankowska EA, Ponikowski P, Lainscak M, Elsner S, Sliziuk V, et al. The impact of iron deficiency and anaemia on exercise capacity and outcomes in patients with chronic heart failure. Results from the Studies Investigating Co-morbidities Aggravating Heart Failure. Int J Cardiol. (2016) 205:6-12. doi: $10.1016 /$ j.ijcard.2015.11.178

13. Michailidou M, Nfonsam VN. Preoperative anemia and outcomes in patients undergoing surgery for inflammatory bowel disease. Am J Surg. (2018). 215:78-81. doi: 10.1016/j.amjsurg.2017.02.016

14. Gomollón F, Gisbert JP. Anemia and inflammatory bowel diseases. World J Gastroenterol. (2009) 15:4659-65. doi: 10.3748/wjg.15.4659

15. Semrin G, Fishman DS, Bousvaros A, Zholudev A, Saunders AC, Correia $\mathrm{CE}$, et al. Impaired intestinal iron absorption in Crohn's disease correlates with disease activity and markers of inflammation. Inflamm Bowel Dis. (2006) 12:1101-6. doi: 10.1097/01.mib.0000235097.86360.04

16. Weiss G, Gasche C. Pathogenesis and treatment of anemia in inflammatory bowel disease. Haematologica. (2010) 95:175-8. doi: 10.3324/haematol.2009.017046

17. Przybyszewska J, Zekanowska E. The role of hepcidin, ferroportin, HCP1, and DMT1 protein in iron absorption in the human digestive tract. Prz Gastroenterol. (2014) 9:208-13. doi: 10.5114/pg.2014. 45102

18. Weiss G, Goodnough LT. Anemia of chronic disease. N Engl J Med. (2005) 352:1011-23 doi: 10.1056/NEJMra041809

19. Dignass AU, Gasche C, Bettenworth D, Birgegård G, Danese S, Gisbert JP, et al. European consensus on the diagnosis and management of iron deficiency and anaemia in inflammatory bowel diseases. J Crohns Colitis. (2015) 9:211-222. doi: 10.1093/ecco-jcc/jju009

20. Goodhand JR, Kamperidis N, Rao A, Laskaratos F, McDermott A, Wahed $\mathrm{M}$, et al. Prevalence and management of anemia in children, adolescents, and adults with inflammatory bowel disease. Inflamm Bowel Dis. (2012) 18:513-19. doi: 10.1002/ibd.21740

21. Nielsen $\mathrm{OH}$, Soendergaard C, Vikner ME, Weiss G. Rational management of iron-deficiency anaemia in inflammatory bowel disease. Nutrients. (2018) 10:82 doi: $10.3390 /$ nu10010082 
22. Bou-Fakhredin R, Halawi R, Roumi J, Taher A. Insights into the diagnosis and management of iron deficiency in inflammatory bowel disease. Exp Rev Hematol. (2017) 10:801-8. doi: 10.1080/17474086.2017.13 55233

23. Lee T, Clavel T, Smirnov K, Schmidt A, Lagkouvardos I, Walker A, et al. Oral versus intravenous iron replacement therapy distinctly alters the gut microbiota and metabolome in patients with IBD. Gut. (2017) 66:863-71. doi: 10.1136/gutjnl-2015-309940

24. Biggar P, Hahn KM. Bedeutung der verschiedenen i.v.-Eisengenerationen für den medizinischen alltag [Importance of the different i.v. iron generations for everyday medical practice]. MMW Fortschr Med. (2013) 155(Suppl. 1):18-24. doi: 10.1007/s15006-013-0732-4

25. Silverstein SB, Rodgers GM. Parenteral iron therapy options. Am J Hematol. (2004) 76:74-8. doi: 10.1002/ajh.2 0056
Conflict of Interest: KF has received speaker's honoraria from AbbVie, Janssen Ferring, Takeda, and Goodwill Pharma. TM has received speaker's honoraria from MSD, AbbVie, Egis, Goodwill Pharma, Takeda, Pfizer, and Teva.

The remaining author declares that the research was conducted in the absence of any commercial or financial relationships that could be construed as a potential conflict of interest.

Copyright (C) 2021 Resál, Farkas and Molnár. This is an open-access article distributed under the terms of the Creative Commons Attribution License (CC BY). The use, distribution or reproduction in other forums is permitted, provided the original author(s) and the copyright owner(s) are credited and that the original publication in this journal is cited, in accordance with accepted academic practice. No use, distribution or reproduction is permitted which does not comply with these terms. 